\title{
SEVERE CUTANEOUS ADVERSE DRUG REACTIONS: STEVENS-JOHNSON SYNDROME AND TOXIC EPIDERMAL NECROLYSISA, A REPORT OF 4 CASES SEEN AT UMMC
}

\author{
Shasha Khairullah, Rokiah Che Ismail \\ Department of Medicine, Faculty of Medicine, University of Malaya, Kuala Lumpur, Malaysia.
}

\begin{abstract}
:
Prescribing medication is not without its adverse effects. Complications due to drug therapy are on the rise in Malaysia, especially when antibiotics are used indiscriminately. We reviewed cases admitted to the Acute Medical Ward of University of Malaya Medical Centre (UMMC), Kuala Lumpur, Malaysia, over a two-month period from March to April 2009. The authors found that Stevens-Johnson Syndrome (SJS) and Toxic Epidermal Necrolysis (TEN) were the most common severe adverse cutaneous reactions due to ingestion or parenteral use of drugs. In this report, is a brief description of the two conditions and ways to manage them. The authors have come to a conclusion that judicious use of medications with adequate patient education is important in order to avoid these adverse effects. (JUMMEC 2010; 13 (1): 50-58)
\end{abstract}

KEYWORDS: Adverse cutaneous drug reactions, Stevens-Johnson Syndrome, Toxic Epidermal Necrolysis

\section{Introduction}

Complications due to drug therapy are the most common types of adverse reactions in hospitalized patients (1). Studies have shown that between $2 \%$ and $6 \%$ of patients are hospitalized due to adverse drug reactions (2). These cutaneous reactions range from macular rash to extensive blistering lesions. Although a majority of cutaneous drug reactions are not severe, immediate recognition can prevent the progression to severe reactions that may result in prolonged hospital stay, increased morbidity and mortality and increasing costs due to usage of medications and laboratory charges (3). In a recent report, based on the findings from a large population of hospitalized Medicare patients in the United States, it was shown that those with adverse drug reaction, which affects only $1.73 \%$ of those hospitalised, incurred $9.15 \%$ more charges on drugs, $2.82 \%$ more on laboratory costs and had an $8.25 \%$ increase in length of hospitalisation (3). This would also inevitably lead to an increase in indirect costs due to prolonged time off from work.

In 2008 alone, the National Centre for Adverse Drug Monitoring of Malaysia has received 4826 local reports of spontaneous adverse drug reactions, an increase of $57.3 \%$ in comparison to the previous year. The most number of adverse drug reactions were attributed to cardiovascular drugs, followed by use of antimicrobials (4). With increasing awareness of the health care professionals and improved reporting, it is predicted that the frequency and number of adverse drug reactions may be on the increase; more so when antibiotics are used indiscriminately.

\section{Case Reports}

In this report, we focus on two types of severe cutaneous adverse drug reactions, i.e Stevens-Johnson Syndrome (SJS) and Toxic Epidermal Necrolysis (TEN).
Correspondence:
Rokiah Che Ismail
Department of Medicine
Faculty of Medicine
University of Malaya
50603 Kuala Lumpur, Malaysia
E-mail: rokiahismail@um.edu.my 
We reviewed the cases admitted to the Acute Medical Ward of the University of Malaya Medical Centre (UMMC), Kuala Lumpur, Malaysia, over a two-month period from March to April 2009. We noted that these two types were the most common severe adverse cutaneous reactions due to ingestion or parenteral use of drugs.

\section{Case Report 1}

A 48-year-old Bangladeshi man presented to his General Practitioner (GP) with low-grade fever and generalized body aches. He was prescribed amoxicillin, paracetamol and multivitamins. Two days later he saw another GP after developing painful ulcerations in the mouth and lesions on his limbs and trunk. He was sent home with cefadroxil (a cephalosporin) and paracetamol. Despite taking the medications, his condition did not improve. He revisited the same GP the next day and was given oral prednisolone and cetirizine. Because his skin lesions were worsening, he sought treatment at the Accident and Emergency Unit (A \& E) of UMMC on the third day after the first ulcerations appeared. At the $A \& E$, the medical officer noted that he had large areas of hyperpigmented lesions with blisters and superficial erosions in some, involving the limbs and trunk along with erythematous superficial ulcerations on the hard palate. He had no previous allergies and noted that he had taken cefalexin (a cephalosporin) and amoxicillin in the past with no adverse reactions. He was then admitted to the Acute Medical Unit under the care of the Dermatologist. The case was reviewed and detailed history including previous drug history was taken. A diagnosis of Toxic Epidermal Necrolysis (TEN) secondary to amoxicillin and cefadroxil was made.

Because of the severity of the drug reaction involving almost $40 \%$ of the skin, he was given intravenous hydrocortisone followed by high dose oral prednisolone. Over the next seven days, the skin lesions improved and he was able to eat. For blisters on the body, he was given wet wraps with dilute solution of potassium permanganate solution (KMnO4). Subsequently when the lesions were drying up, topical steroid creams were applied. He was discharged on the tenth day with $40 \mathrm{mg}$ of prednisolone daily and advised on a tapering dose of the steroid within the next two weeks. From the history of his previous exposure to amoxicillin and cephalosporin, it could have been that he had his sensitising dose then.

\section{Case Report 2}

A 48-year-old Indian lady with type 2 diabetes mellitus, below-knee amputation of the left leg and a right diabetic foot ulcer, was admitted with abdominal pain and distension, associated with nausea and breathlessness. She also had fever with poor urine output. An initial diagnosis of nephrotic syndrome and sepsis secondary to the right diabetic foot ulcer was made. Intravenous Unasyn (ampicillin and sulbactam) was given after blood cultures were taken. She was also given intravenous frusemide for the fluid retention.

On the fifth day of admission, she developed erythematous, target-like, blistering lesions on the dorsum of her right hand and on the antecubital fossa of her left arm (Figures $1 \mathrm{a}$ and 1b). These lesions appeared around the area of the branula site. The initial impression was that these lesions could have been caused by the extravasation of the antibiotics into the tissue around the branula. She gave no past history of adverse reactions to any medication. She was prescribed dilute potassium permanganate soaks to the areas of the blisters. One percent hydrocortisone cream was prescribed topically on the non blistered target lesions.

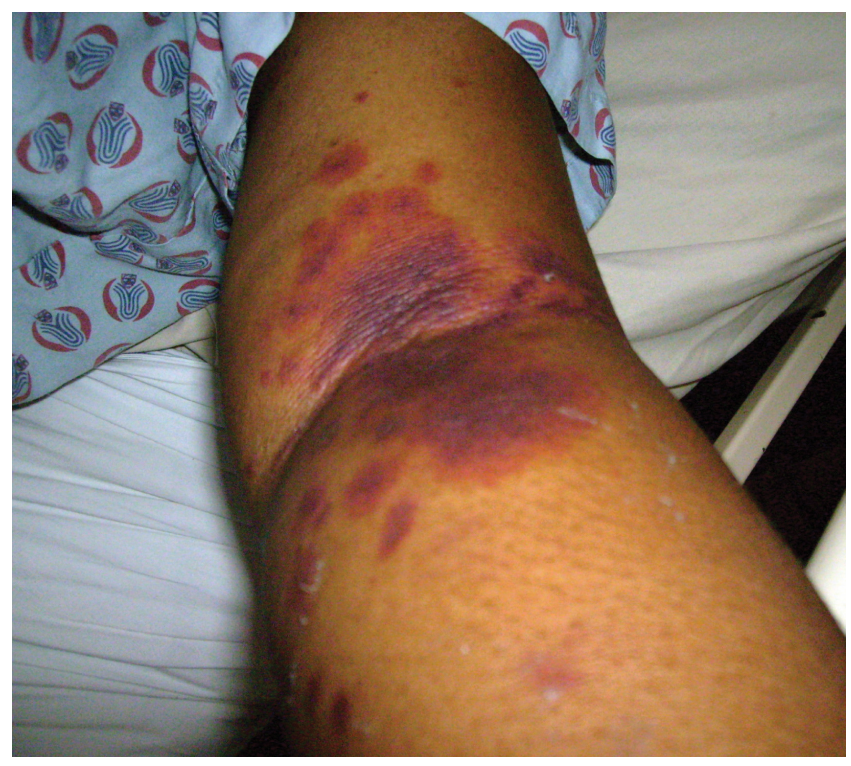

Figure 1a: 48-year- old female with Bullous Erythema Multiforme 

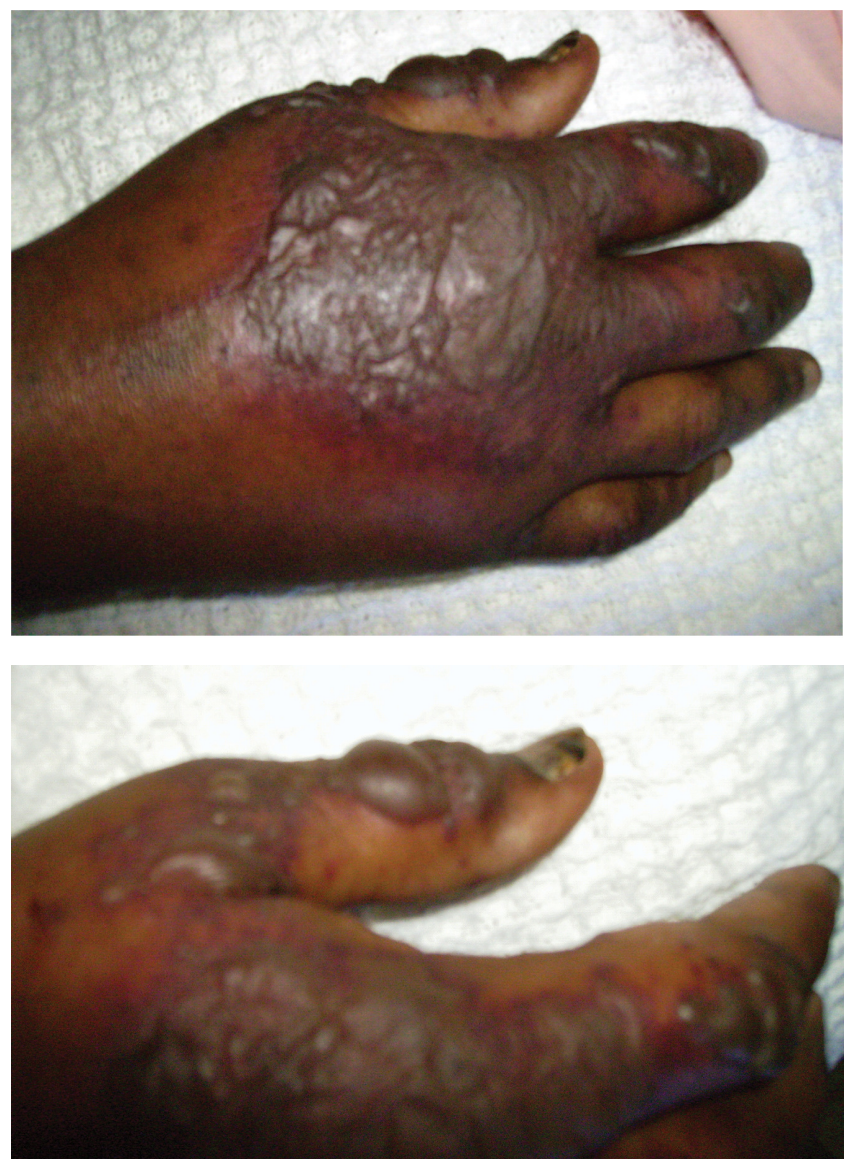

Figure 1b: Same patient showing bullous eruptions on the dorsum of the hand

Over the next two days, the lesions progressed, involving both limbs and the upper part of her trunk. She was then started on intravenous hydrocortisone. A diagnosis of bullous erythema multiforme secondary to ampicillin and sulbactam (Unasyn) was made.

\section{Case Report 3}

A 44-year-old Malay man, with a background history of nephritic syndrome secondary to focal segmental glomerulosclerosis, chronic renal disease and hypertension, was seen by a General Practitioner (GP) for fever, sore throat and itchiness of his eye. He was initially prescribed cefixime (a cephalosporin) and then a week later, was given amoxicillin clavulanate (Augmentin) and paracetamol. One day after taking amoxicillin clavulanate, he developed rashes around his neck. He however continued taking the medication. Three days later, the rashes became worse and the fever persisted.
He presented to the A\&E of UMMC on the third day after the rash appeared and was admitted with red eyes, mucosal erosions and multiple target lesions, some of which were confluent, over the trunk and limbs. He also developed difficulty and pain on swallowing. He suffers from seafood allergy but has no known previous allergies to drugs.

He was admitted to the Acute Medical ward under the Dermatology unit. The next day, we requested a list of medications from his GP whom he had visited four times in the past one month, for various complaints. He was on a number of drugs namely colchicine, allopurinol, ibuprofen, meloxicam, simvastatin, cefuroxime and amoxicillin clavulanate.

As his renal profile was deranged and he had worsening of the renal functions, (urea $=24.4 \mathrm{mmol} / \mathrm{l}$, creatinine $=809 \mu \mathrm{mol} / \mathrm{l}$ ) an ultrasound scan of his kidneys was done which showed bilateral renal parenchymal disease. A diagnosis of toxic epidermal necrolysis possibly due to cefuroxime, allopurinol and or amoxicillin clavulanate was made. He was put on intravenous hydrocortisone and subsequently a tapering-down course of oral prednisolone. For the skin lesions, wet wraps with dilute potassium permanganate were done. The patient recovered fully and was discharged ten days later. He was advised on the medications that he should not take and was given a medic alert badge with allergies to cefuroxime, allopurinol and amoxicillin clavulanate.

\section{Case Report 4}

A 28-year-old man who sustained head injuries during a road traffic accident, was admitted to the UMMC Intensive Care Unit (ICU). During his one-month stay in ICU, he was started on several intravenous antibiotics at different intervals, amoxicillin clavulanate, piperacillin tazobactam (tazocin), polymyxin and ampicillin sulbactam (unasyn). He was later transferred to the Neurosurgical ward. There he developed a nosocomial infection. He was given intravenous amoxicillin clavulanate for three days. On the sixth day of hospital stay in the neurosurgical ward, he noticed an erythematous rash associated with pruritus starting at the neck and left antecubital fossa. He was also started on cetirizine and ponstan. His rash improved. 


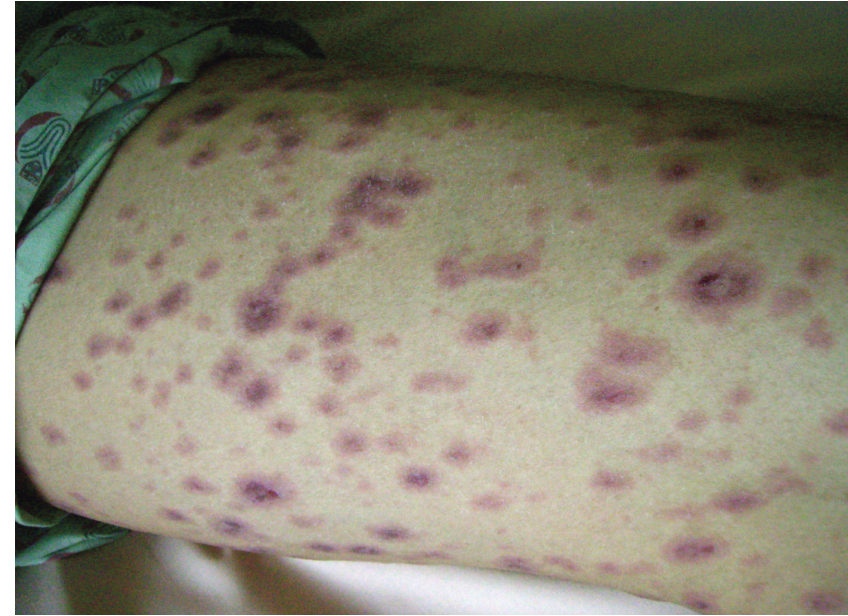

Figure 2a: A 28 -year-old male with SJS showing target lesions.

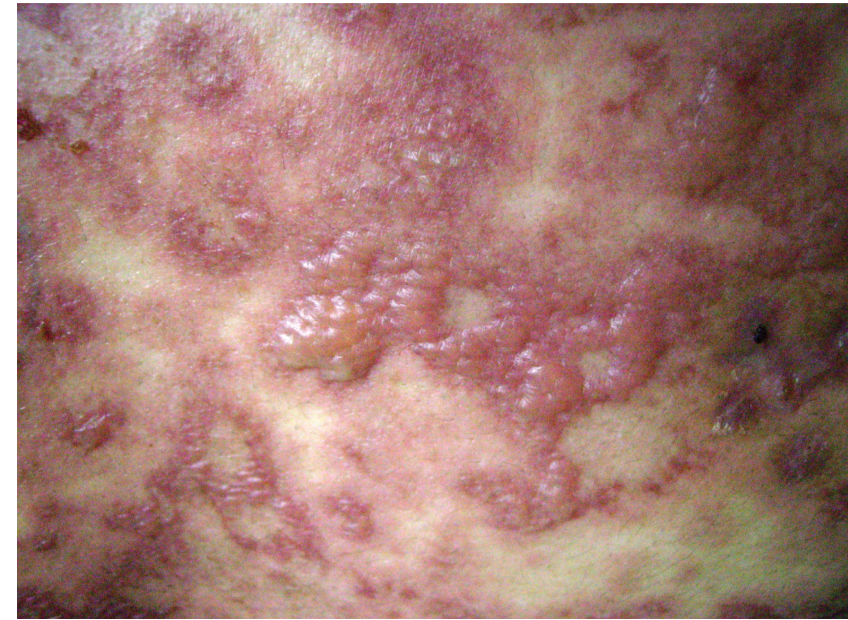

Figure 2b: Same patient showing superficial blisters appearing on the trunk

Table 1: Summary of similarities between the four cases.

\begin{tabular}{|c|c|c|c|c|}
\hline & Case 1 & Case 2 & Case 3 & Case 4 \\
\hline Known drug allergies & $\mathrm{Nil}$ & $\mathrm{Nil}$ & $\mathrm{Nil}$ & $\mathrm{Nil}$ \\
\hline $\begin{array}{l}\text { Common Drug } \\
\text { Denominators seen: }\end{array}$ & $\begin{array}{l}\text { Amoxicillin, } \\
\text { Cefadroxil }\end{array}$ & $\begin{array}{l}\text { Ampicillin } \\
\text { Sulbactam } \\
\text { (Unasyn) }\end{array}$ & $\begin{array}{l}\text { Cefuroxime, } \\
\text { Amoxicillin } \\
\text { clavulanate } \\
\text { (Augmentin), } \\
\text { Allopurinol }\end{array}$ & $\begin{array}{l}\text { Amoxicillin } \\
\text { clavulanate } \\
\text { (Augmentin) }\end{array}$ \\
\hline $\begin{array}{l}\text { Previous exposure to } \\
\text { drugs: }\end{array}$ & $\begin{array}{l}\text { Treated with cefalexin } \\
\text { and amoxicillin in the } \\
\text { past. }\end{array}$ & $\begin{array}{l}\text { No previous use of } \\
\text { ampicillin sulbactam } \\
\text { recorded. }\end{array}$ & $\begin{array}{l}\text { Treated with } \\
\text { cefuroxime, } \\
\text { amoxicillin } \\
\text { clavulanate and } \\
\text { allopurinol in the past. }\end{array}$ & $\begin{array}{l}\text { Treated with } \\
\text { intravenous } \\
\text { amoxicillin } \\
\text { clavulanate on two } \\
\text { occasions. }\end{array}$ \\
\hline $\begin{array}{l}\text { Re-challenged with } \\
\text { current drugs. } \\
\text { Shortened onset of } \\
\text { symptoms. }\end{array}$ & $\begin{array}{l}\text { 2nd day of antibiotic } \\
\text { use }\end{array}$ & $\begin{array}{l}\text { 5th day of antibiotic } \\
\text { use }\end{array}$ & $\begin{array}{l}\text { 2nd day of antibiotic } \\
\text { use }\end{array}$ & $\begin{array}{l}\text { 6th day of antibiotic } \\
\text { use }\end{array}$ \\
\hline Diagnosis: & $\begin{array}{l}\text { Toxic Epidermal } \\
\text { Necrolysis (TEN) }\end{array}$ & $\begin{array}{l}\text { Bullous Erythema } \\
\text { Multiforme (BEM) }\end{array}$ & $\begin{array}{l}\text { Toxic Epidermal } \\
\text { Necrolysis (TEN) }\end{array}$ & $\begin{array}{l}\text { Steven Johnson } \\
\text { Syndrome (SJS) }\end{array}$ \\
\hline \begin{tabular}{|l} 
Response to \\
corticosteroids.
\end{tabular} & $\begin{array}{l}\text { Discharged after } 10 \\
\text { days of admission. }\end{array}$ & $\begin{array}{l}\text { Rashes improved after } \\
12 \text { days. Was not } \\
\text { discharged as she had } \\
\text { other comorbidities }\end{array}$ & $\begin{array}{l}\text { Discharged after } 10 \\
\text { days of admission. }\end{array}$ & $\begin{array}{l}\text { Discharged after } 7 \\
\text { days of admission. }\end{array}$ \\
\hline
\end{tabular}

Table 1 summarises the similarities between the 4 cases seen. In 3 of the cases seen, sensitisation to the drug had occurred previously when the patients were exposed to the initial dose. The last case (case \# 4) was sensitised during the admission to the UMMC for his head injury where he was given amoxicillin clavulanate.

After a week, he was discharged with amoxicillin clavulanate, and cetirizine. The rashes worsened after one day and started to spread to the upper and lower limbs, chest and abdomen. He was readmitted the next day with widespread painful maculopapular rash and joint pain. Blisters were present, especially on the trunk, palmar aspects of his hands, dorsum and sole of his feet (Figure $2 \mathrm{a}$ and $2 \mathrm{~b}$ ). He also had oral ulcers and areas of superficial erosions on his penis.

He was referred to the Dermatology team, who saw the patient and a diagnosis of SJS secondary 
to amoxicillin clavulanate was made. $\mathrm{He}$ was started on oral prednisolone, dilute potassium permanganate topically to the areas of blisters and additional topical creams to the erythematous, non blister areas.

The patient recovered and was discharged one week later.

In relation to the four cases above, the similarities are highlighted in Table 1.

\section{Discussion}

\section{Epidemiological Data And Clinical}

SJS and TEN are two related mucocutaneous reactions characterised by blistering lesions involving the epidermal region of the skin and erosions of the mucous membrane. The incidence are 1 to 6 and 0.4 to 1.2 per million person-years respectively $(1,5)$.

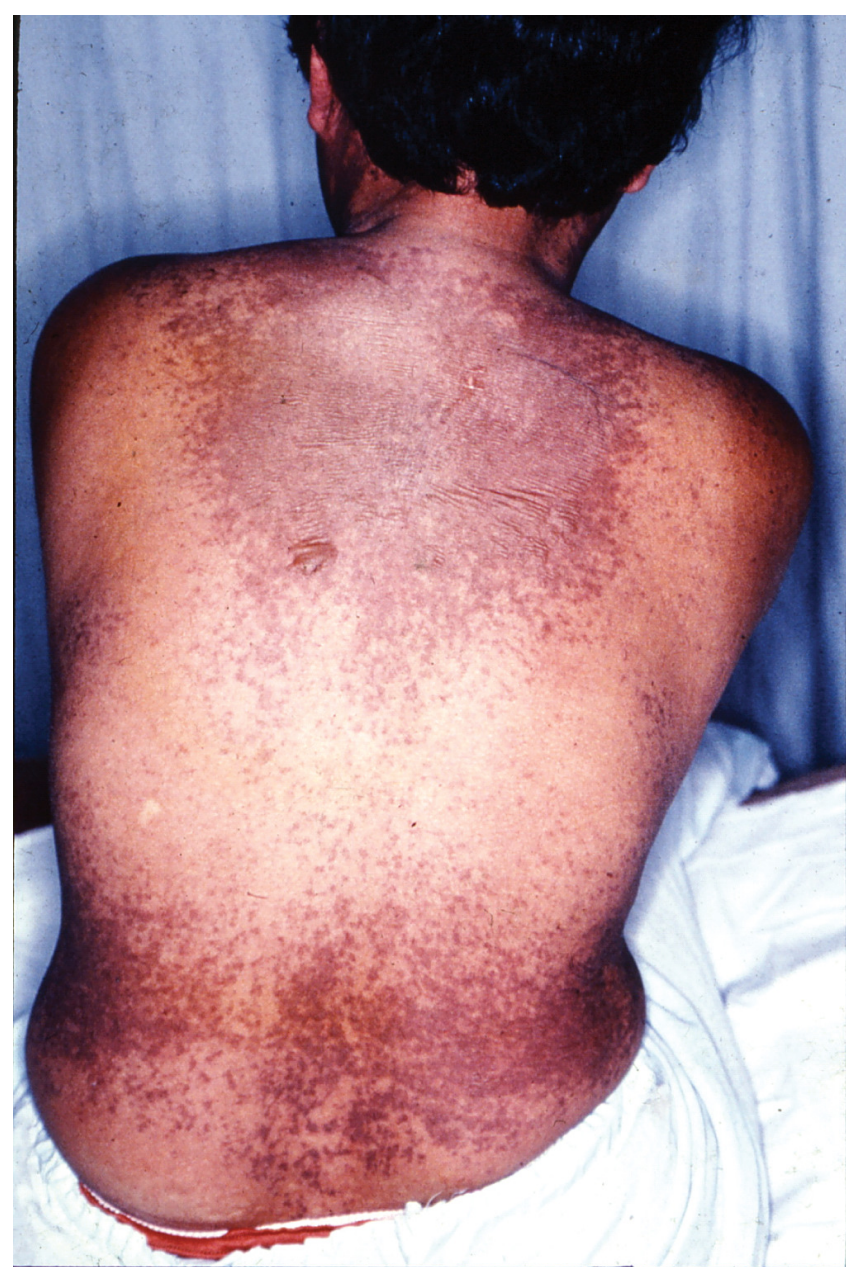

Figure 3: TEN-Slide of another patient with a similar condition
The spectrum of cutaneous drug reactions range from the mild macular-papular erythematous rashes to fixed drug eruptions, erythema multiforme (EM), bullous erythema multiforme (BEM), Steven Johnson Syndrome (SJS) and the most severe which can lead to significant mortality, toxic epidermal necrolysis (TEN). (Table 2).

Table 2: The spectrum of Adverse Cutaneous Drug Reactions

\begin{tabular}{|l|}
\hline Maculopapular rash \\
Bullous Erythema Multiforme \\
Erythema Multiforme Major \\
Stevens-Johnson Syndrome \\
Toxic Epidermal Necrolysis
\end{tabular}

Table 2 summarises the spectrum of cutaneous drug reactions ranging from mild maculopapular rash to life-threatening TEN

The usual mild forms of cutaneous drug reactions include dusky erythema without blisters as in erythema multiforme, target lesions, where there is some degree of ischaemia to the superficial layer of the skin, to the most severe form involving separation of the epidermis from the dermis as in toxic epidermal necrolysis (TEN), whereby sheets of the epidermis separate out from the dermis. (Figure 3) This is the most severe, and in some cases, can be fatal if prompt treatment is not instituted (6).

SJS and TEN have a strong association with specific medication. In most studies, it has been shown that the rates of exposure to certain types of drugs are similar in SJS, SJS-TEN overlap and TEN $(1,5,7,8)$. Around $50 \%$ of SJS and more than $80 \%$ of TEN is caused by drugs $(1,9,10)$. The list of drugs with the most significant association are shown in Table 3 . The risk was found to be highest within a period of 4 to 28 days between the first initiation of the drug and onset of adverse reaction (10). Adverse drug reactions occur more frequently in recent times partly due to improper use of antibiotics, as can be seen in the cases highlighted above. Antibiotics are most commonly prescribed for 
Table 3: Medications associated with high risk of SJS or TEN ${ }^{10}$

$$
\begin{aligned}
& \text { Antibiotics: } \\
& \text { - Cotrimoxazole } \\
& \text { - Anti-infective sulfonamides } \\
& \text { Sulfasalazine } \\
& \text { Allopurinol } \\
& \text { Anti-inflammatory drugs: } \\
& \text { - Sulfasalazine } \\
& \text { - Oxicam-NSAIDs } \\
& \text { Antiepileptic drugs: } \\
& \text { - Lamotrigine } \\
& \text { - Carbamezapine } \\
& \text { - Phenytoin } \\
& \text { - Phenobarbital } \\
& \text { Antiretroviral: } \\
& \text { - Nevirapine }
\end{aligned}
$$

Table 3 summarises the list of drugs that are regularly associated with causing SJS or TEN.

upper respiratory tract infections, as is the case of three of the cases above (11). Other risk factors include HIV infection, cancer and collagen vascular disease (7). The high risk reflects frequent drug use in comparison to the general public.

The immune system is thought to play a role in most adverse drug reactions including those which involve the skin (12). There have been many papers that postulate an immunological reaction to drugs as the cause of SJS and TEN $(1,12)$. This is further strengthened by the fact that SJS and TEN can recur within 48 hours of a rechallenge, in comparison to an average of 14 days after initial reaction (1). This is because it takes around two weeks of continuous treatment for sufficient antibodies to develop and cause a reaction. Some drugs, like antibiotics, are used for five to seven days and therefore the antibodies produced are not adequate to cause a reaction. However, when the offending drug is unknowingly re-introduced to the patient, this would cause a sensitisation effect as can be seen in the cases above, mounting a severe reaction within a short period of time.

The hapten hypothesis has been used to explain the immunological mechanism of SJS and TEN (12). Not only is the skin equipped with an active immunological defence system, it is also able to metabolise drugs. The hypothesis proposes that drugs or the reactive metabolites of the drugs, act as haptens which bind covalently to endogenous proteins (which in this case would be the epidermal proteins) forming a compound that would trigger the immune system (12). The epidermis is then infiltrated with activated lymphocytes, mostly CD8 cells and macrophages (1, 12)

With the two disorders, sepsis is the major cause of death. Visceral involvement, increased urea and creatinine and extensive epidermal detachment indicate poor prognosis (1). However, prognosis is not affected by HIV infection or the type and dosage of drug used.

\section{Histopathology}

SJS and TEN are shown to be similar in terms of histopathological findings. Very severe cases of SJS may include large areas of patchy epidermal necrolysis with bullae and target lesions; while in TEN there would be large areas of the body with sheets of epidermis separating from the dermis. The difference noted between the two are the extent of epidermal detachment, which is more pronounced (>30\%) in TEN causing a higher mortality rate (7). Cases that involve epidermal detachment between 10 to $30 \%$ are considered an overlap of the two syndromes $(1,6$, $7)$.

In most cases, a skin biopsy is not necessary as it does not help in determining the cause, whether it is druginduced or not. A diagnosis of adverse cutaneous drug reaction, either SJS or TEN, can be made with a careful and detailed history as well as an accurate account and confirmation of the previous medications taken and the time sequence of the occurrence of the typical lesions, usually gives an accurate clinical impression. This is further enhanced by finding the typical lesions on the skin (target lesions, with or without intraepidermal blisters, and a positive Nikolsky sign, and or superficial erosions on the mucous membranes). A re-challenge with the likely causative drug, although NOT usually done because of the possible severe reaction which can be life-threatening, may confirm the definite drug causing the reaction. However, this is not advisable because 
it is unethical to subject a patient to a possibly lifethreatening test.

\section{Management}

Adverse cutaneous drug reactions, if severe, like SJS and TEN, should be recognized as an acute dermatologic emergency and therefore, should be managed on the wards. Depending on the severity and the extent of the skin involvement, it may be necessary to have the patient monitored in the intensive care unit or the burns unit.

The management is similar to that of a patient with thermal burns which includes aggressive fluid replacement, nutritional support special attention given to ensure that the patient gets a high protein diet; if there is sepsis, careful choice of antibiotics is absolutely essential, to prevent more reactions; aseptic handling and avoidance of adhesive material and proper skin care with open dressings and the use of dilute potassium permanganate wet wraps will assist in the prevention of superficial infection and allows the healing process to occur. Hence, optimal nursing care is vital to ensure a smooth and rapid recovery. Also all potentially responsible medication should be withdrawn immediately. All drugs, especially those introduced within a month of the reaction should be considered suspect (1).

Most therapies by administering corticosteroids or other disease-modifying therapies have yet to be proven for their effectiveness by controlled studies. There has been much debate on whether corticosteroids should be used in the treatment of SJS and TEN $(1,6$, 13). Therapeutic use of systemic corticosteroids have been advocated in some studies (6) and have been found inconclusive in others (13). Although toxic epidermal necrolysis can develop in patients receiving high-dose corticosteroid therapy (10), recent studies have not found a direct causal effect (14). Others like plasmapheresis and immunoglobulin therapy have been attempted but their effectiveness remain doubtful. Most papers suggest aggressive supportive treatment should be the main priority instead. From our experience, as can be seen in all four cases above, the use of corticosteroids is beneficial in improving and reducing further advancement of skin lesions.

\section{Conclusion}

The diagnosis and management of SJS and TEN are complex and controversial. As these conditions are associated with devastating sequelae, more effort should be made to clarify the classification of clinical features of this disorder. It is important for physicians to promptly recognize the signs and symptoms as only early intervention is best at this point in time. Drug-induced reactions should always be part of the differential diagnosis for any adverse reaction. Even if a certain drug borders on 'probable' that drug should be withdrawn. At UMMC, any allergic or adverse reaction to a drug is notified to the Malaysian Adverse Drug Reactions Advisory Committee (MADRAC) via a written form. After recovery, patients should be advised to subscribe to MedicAlert, to obtain some form of identification in order to prevent future occurences; and avoid the drug and all its chemically-related compounds.

A multidisciplinary approach is required to manage these two conditions. Regular and consistent input is needed from the dermatologists and the plastic surgeons to reduce progression of the skin lesions. The nursing staff plays a vital role in ensuring that the proper skin care and dressings are carried out. Nutritionists are also involved as a high-protein diet is known to speed up the healing process.

In Malaysia, where the practice of "doctor shopping" is common, it is essential that patient education be emphasised as an important part of patient management. This should be taken up by medical schools to ensure that this component is part of their undergraduate curriculum.

With the increasing awareness of health care professionals and improved reporting, it is predicted that the frequency and number of patients with adverse drug reactions may be on the increase; more so when antibiotics are used indiscriminately. Over-prescribing antibiotics can also lead to antibiotic resistance, resulting in ineffective treatment of infections. In fact, the World Health Organization identified this issue as one of the threats to global public health security and suggested the urgent need to promote judicious and rational antibiotic prescribing practices (15). The cases above could have been avoided had there been careful 
use of medication, especially antibiotics. Clinicians should not succumb to the pressure of prescribing antibiotics just to please their patients. Antibiotics should be prescribed only if they are proven to be beneficial to the patient.

Although the likelihood of a severe reaction is very slim, less than 1 reaction per 5000 exposed patients, they are mostly undetected in premarketing clinical trials (1). Therefore it is the clinician's responsibility to detect and report these reactions to the regulatory bodies, when they do occur. In Malaysia, all drug-induced reactions should be reported to the Malaysian Adverse Drug Reactions Advisory Committee (MADRAC). The report can be made by filling up blue cards which are available at the hospital or submitted via the Internet at their website (16).

The current practice of prescribing and dispensing of medicines done at private clinics and dispensaries should be reviewed. With the increasing numbers of adverse cutaneous drug reactions seen recently , the authors suggest that prescribing of drugs should be done judiciously and with adequate patient education. Patient should also be given information of the effects and possible side effects of the drugs prescribed. This should be re-emphasised when the drugs are dispensed by the pharmacists. The authors believe that the prevalence of adverse drug reactions, may, to some extent be reduced if there is a separation between prescribing and dispensing of the drugs as is practiced in hospitals in this country.

\section{Acknowledgements}

We would like to thank our colleagues for their support. We are also grateful to the nursing staff of Ward $12 \mathrm{U}$ (UMMC) for their dedication in caring for these patients.

\section{References}

1. Roujeau JC, Stern RS. Severe adverse cutaneous reactions to drugs, N Eng J Med 1994; 331: 12721285.

2. Fiszenson-albala $F$, et al. A 6-month prospective survey of cutaneous drug reactions in a hospital setting. Bri J Dermatol 2003; 149: 1018-1022.
3. Bond CA, et al. Adverse Drug Reactions in United States Hospitals. Pharmacotherapy 2006; 26(5): 601-608.

4. Adverse Drug Reactions (ADR) Reports for 2008and overview. Malaysian Adverse Drug Reactions Newsletter. http://www.bpfk.gov.my. Accessed 5 Aug 2009.

5. Roujeau JC, et al. Medication use and the risk of Stevens-Johnson syndrome or toxic epidermal necrolysis. N Eng J Med 1995; 333: 1600-1607.

6. Patterson $\mathrm{R}$, et al. Erythema multiforme and Stevens-Johnson syndrome: Descriptive and therapeutic controversy. Chest 1990; 98: 331336.

7. Auquier-Dunant A, et al. Correlations between clinical patterns and causes of erythema multiforme majus, Stevens-Johnson syndrome and toxic epidermal necrolysis. Results of an international prospective study. Arch Dermatol 2002; 138: 10191024.

8. Bastuji-Garin S, et al. Clinical classification of cases of toxic epidermal necrolysis, Stevens-Johnson syndrome and erythema multiforme. Arch Dermatol 1993; 129:92-96.

9. Schopf E, et al. Toxic Epidermal Necrolysis and Stevens-Johnson syndrome: An epidemiologic study from West Germany. Arch Dermatol 1991; 127: 839-842.

10. Roujeau JC, et al. Toxic Epidermal Necrolysis (Lyell syndrome): Incidence and drug etiology in France, 1981-1985. Arch Dermatol 1990; 126: 37-42.

11. Yasmin AM. Judicious use of amoxicillinclavulanate in acute upper respiratory infections: Part 1, Malaysian Medical Association Newsletter CME, 2009; 1.

12. BK Park, et al. Metabolic activation in drug allergies. Toxicol 2001; 158: 11-23.

13. Schneck J, et al I. Effects of treatments on the mortality of Stevens-Johnson syndrome and toxic epidermal necrolysis: a retrospective study on patients included in the prospective EuroSCAR study. J Am Acad Dermatol 2008; 59(5): 898-899. 
14. Mockenhaupt $M$, et al. Stevens-Johnson syndrome and toxic epidermal necrolysis: assessment of medication risks with emphasis on recently marketed drugs. The EuroSCAR study. I Invest Dermatol 2008; 128: 35-44.

15. The World Health Report 2007, World Health Organization (WHO). http://www.who.int/entity/ whr/2007/whr07_en.pdf. Accessed 10 Aug 2009.
16. Malaysian Adverse Drug Reactions Advisory Committee (MADRAC) website. http://www.bpfk. gov.my. Accessed 5th Aug 2009. 